\title{
Shockwave intravascular lithotripsy as a novel strategy for balloon undilatable heavily calcified chronic total occlusion lesions
}

\author{
Piotr Rola ${ }^{1,2}$, Adrian Włodarczak ${ }^{1}\left({ }^{\infty}\right.$, Mateusz Barycki $^{2}$,, Maciej Pęcherzewski ${ }^{1}$, \\ Jan Jakub Kulczycki ${ }^{1}$, Marek Szudrowicz ${ }^{1}$,, Artur Jastrzębski ${ }^{1}$, \\ Łukasz Furtan ${ }^{1}$, Adrian Doroszko ${ }^{3}$ (D), Maciej Lesiak ${ }^{4}$ (D) \\ ${ }^{1}$ Department of Cardiology, The Copper Health Centre (MCZ), Lubin, Poland \\ ${ }^{2}$ Poland Department of Cardiology, Provincial Specialized Hospital in Legnica, Poland \\ ${ }^{3}$ Department of Internal Medicine, Hypertension and Clinical Oncology, \\ Wroclaw Medical University, Wroclaw, Poland \\ ${ }^{4} 1^{\text {st }}$ Department of Cardiology, Poznan University of Medical Sciences, Poznan, Poland
}

\begin{abstract}
Background: The successful percutaneous coronary intervention (PCI) in chronic total occlusion (CTO) improves the long-term outcome in patients with coronary artery disease (CAD). Heavy calcification remains one of the strongest predictors of an unfavorable outcome of PCI. In this case series study, shockwave intravascular lithotripsy (S-IVL)-a novel balloon-based coronary system facilitating modification of calcified coronary lesions was evaluated.

Methods: The study population consisted of five heavily calcified, undilatable-CTOs lesions treated with S-IVL selected out of all consecutive CTO-PCI patients performed at two high-volume cardiac centers.

Results: The registry included 5 patients successful CTO $-S$-IVL procedures with an average J-CTO of 2.6 points. In the short-term follow-up period, including the first 30 days, no cases of acute in-stent thrombosis, target lesion failure, or major adverse cardiac and cerebrovascular events were noted.

Conclusions: The present data suggest that this approach can be safe and useful in the treatment of complex calcified CTO lesions. (Cardiol J)

Key words: chronic total occlusion, coronary artery disease, percutaneous coronary intervention, shockwave intravascular lithotripsy, calcified lesions, undilatable lesions, chronic stable angina
\end{abstract}

\section{Introduction}

A coronary chronic total occlusion (CTO) is defined as complete occlusion of a coronary artery for a duration of greater than 3 months based on angiographic evidence. Approximately one-quarter of patients undergoing diagnostic coronary angiography, CTO-lesions can be found [1,2]. Advances in the percutaneous coronary intervention $(\mathrm{PCI})$ techniques in the management of CTO have improved the success rate of this procedure in over $80 \%$ of high-volume expert centers, however, data from the "real-life" registry suggests that the success rate is far below the mentioned level, achieving approximately $60 \%$ [3]. As it was proven, the successful CTO PCI procedure improves the

Address for correspondence: Piotr Rola, MD, PhD, Department of Cardiology, Provincial Specialized Hospital Legnica, ul. Iwaszkiewicza 5, 55-220 Legnica, Poland, tel: +48 767211443/+48 888272007, fax: +0048 7672110, e-mail: piotr.rola@gmail.com

Received: 17.07.2021 Accepted: 28.08.2021 Early publication date: 23.09.2021

This article is available in open access under Creative Common Attribution-Non-Commercial-No Derivatives 4.0 International (CC BY-NC-ND 4.0) license, allowing to download articles and share them with others as long as they credit the authors and the publisher, but without permission to change them in any way or use them commercially. 
long-term outcome of patients with coronary artery disease (CAD) [4]. Despite apparent clinical benefits, the risk of complications associated with these complex PCI procedures is significantly higher, compared to the non-CTOs [5].

To have better planning and to predict the short-term outcome, the J-CTO-score was proposed as an angiographic scale of the degree of difficulty of CTO-PCI [6]. One of five variables that increase the difficulty of the PCI-CTO procedure, in this well-validated scale, is the presence of calcifications in the body of the occlusion. A similar relationship between target lesion calcification and clinical outcome is observed in non-CTO PCI procedures [7]. The crucial mechanism leading to these unfavorable results is mainly connected with short- and long-term stent failure (fracture, poor expansion, malapposition followed by an increased rate of stent thrombosis and in-stent restenosis). Furthermore, calcifications increase the rate of peri-procedural complications particularly, life-threatening coronary artery perforation [8].

A proper lesion preparation before stent implantation has been established as a prerequisite to achieving adequate PCI results. Numerous strategies aimed at the crossing and appropriate preparation of calcified plaques have been implemented in the CTO-tool box [9]. Conventional procedures were divided into the balloon-dependent group (non-compliant $[\mathrm{NC}]$, ultrahigh-pressure balloon (OPN) or cutting/scoring catheter) exerting an internal pressure on the lesion, and atherectomy devices (rotational, laser, and orbital) focused on removing (pulverizing) the atherosclerotic plaque. Therefore, calcified lesions continue to be one of the most challenging CTO interventions, where optimal angiographic results and satisfying long-term outcomes are hard to achieve.

A recent study [10] suggests that shockwave intravascular lithotripsy (S-IVL) (Shockwave Medical Inc., Fremont, United States) a novel balloon-based coronary system converting electrical energy into mechanical force (acoustic wave with high-pressure amplitude) can facilitate modification of heavily calcified coronary lesions. Presented herein is early real-world experience with the S-IVL device in the setup of the CTO procedure.

\section{Methods}

The study population consisted of 5 carefully selected cases out of all consecutive patients with clinical indications for CTO-PCI at the documented cardiac centers from May 2019 to April 2021. All patients were treated in two high-volume interventional cardiology centers (conducting over 1000 PCI procedures each annually). From all pre-screened cases (192), patients were selected with mild and severe calcification (102 patients). Calcific deposits were assessed by angiography as mild (spots), moderate (involving $\leq 50 \%$ of the reference lesion diameter), and severe (involving $>50 \%$ of the reference lesion diameter). From this group, patients with "undilatable" lesions were selected. For the purpose of this paper the balloon undilatable, CTOs lesions were defined as lesions after the successful crossing of a guidewire through the CTO-body and initial successful pre-treatment with a low diameter $\mathrm{NC}$ balloon $(\mathrm{NCB})$ catheter or with rotational atherectomy (RA) (4 cases of RA in prescreened 192 CTO procedures - all performed due "uncrossable" lesion with a low-profile balloon catheter or microcatheter) with coexisting significant (over $20 \%$ of the diameter) under expansion with NCB size 1:1 to vessel diameter inflated with high-pressure inflation at least of $20 \mathrm{~atm}$.

There were no angiographic exclusion criteria regarding lesion anatomy such as the length, tortuosity, severity, prior stent placement or, J-CTO score. Figure 1 provides the details on the "lesion-related" angiographic and periprocedural inclusion criteria to this registry. Safety parameters, including coronary perforation, no-reflow, ventricular arrhythmias, and the major adverse cardiac and cerebrovascular events (MACCE) that occurred in-hospital and 30-day after primary hospitalization, were recorded. MACCE was defined as a composite endpoint including acute coronary syndrome, cerebrovascular events, major bleeding, need for repeated revascularization, or death.

Ethical review and approval were waived for this study due to the fact that it is a retrospective analysis of clinical cases and the techniques used in this study were used as bail-out techniques in order to save lives, however, patient written informed consent for PCI procedure was given as well as the use of patient information and images.

\section{Case 1}

A 66-year-old female with hypertension, hyperlipidemia, diabetes type 2 , history of non ST-segment elevation myocardial infarction (NSTEMI) 1 year prior, treated with PCI and 3 drug eluting stent (DES) implantations to the left anterior descending (LAD) and D1, was admitted to our center to perform the stage procedure of CTO-right coronary artery (RCA) (J-CTO score 3 points) (Fig. 2.1A) due to recurrent angina 


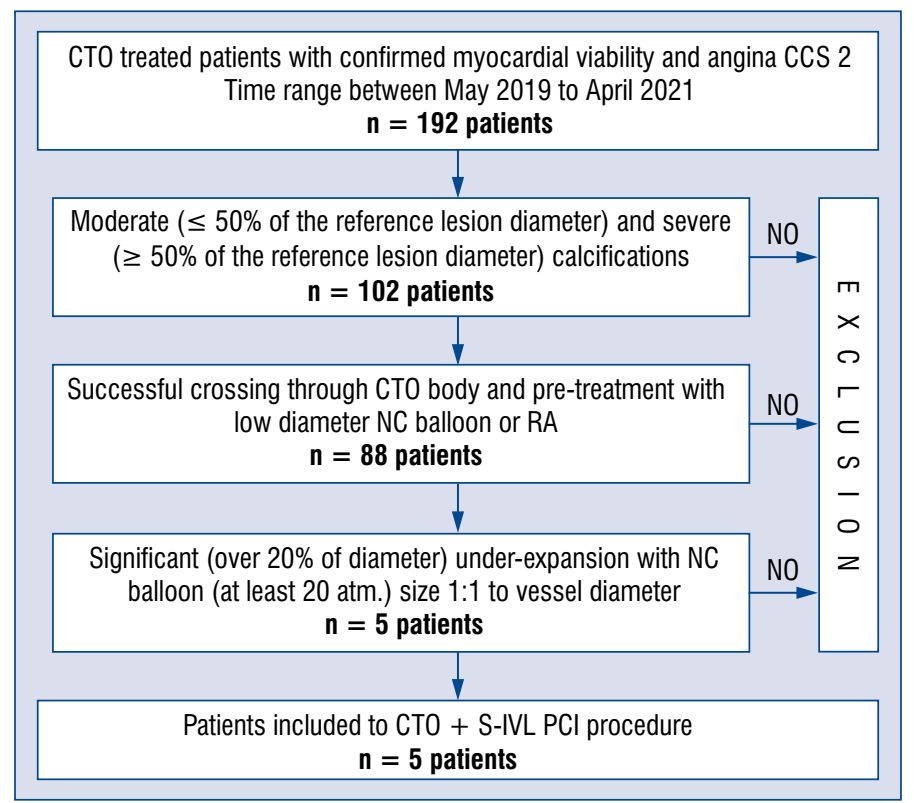

Figure 1. Lesion-related angiographic and procedural inclusion and exclusion criteria to the study; CTO — chronic total occlusion; CCS - Canadian Cardiovascular Society scale; NC — non-compliant; S-IVL — shockwave intravascular lithotripsy; $\mathrm{PCl}$ - percutaneous coronary intervention; RA — rotational atherectomy.

(Canadian Cardiovascular Society [CCS] II) and confirmed myocardial viability in transthoracic echocardiogram (transthoracic echocardiography with the left ventricular ejection fraction $60 \%$ ). PCI was performed via right femoral access (AL 1.0 7F) and contralateral injection by left radial JL $4.0(6 \mathrm{~F})$.

Using several guidewires Fielder XT (AsahiINTECC); Progress 140 (Abbott Vascular, SantaClara, United States) the distal part of RCA with Gaia3 (Asahi-INTECC) was achieved. Despite the use of the 7F guiding extension Guidezilla (Boston Scientific, Marlborough, United States) all attempts of crossing the lesion with the microcatheter and a low-profile balloon $1.0 \mathrm{~mm} \times 10 \mathrm{~mm}$ failed. Considering the severe calcifications, the successful crossing of a lesion was achieved with Turnpike Gold135 (Vascular Solutions LLC, Minneapolis, United States) - microcatheter with threaded tip. In the next step multiple successful high-pressure inflation was performed (Fig. 2.1B) with balloon catheters $1.0 \mathrm{~mm} \times 10 \mathrm{~mm} ; 1.5 \mathrm{~mm} \times 15 \mathrm{~mm}$, and NCB $2.5 \mathrm{~mm} \times 15 \mathrm{~mm}$.

Despite lesion preparation we observed a significant "dogbone effect" on the NCB $3.0 \mathrm{~mm} \times$ $\times 15 \mathrm{~mm}$ (21 atm.) (Fig. 2.1C). Hence, the S-IVL using a $3.0 \mathrm{~mm} \times 12 \mathrm{~mm}$ catheter was performed. Delivery of the device was facilitated by guide extension. After the application of 80 ultrasonic pulses, full expansion was obtained
(Fig. 2.1D). Three overlapping DES $3.5 \mathrm{~mm}$ $\times 15 \mathrm{~mm} ; 3.0 \mathrm{~mm} \times 38 \mathrm{~mm}$ and $3.0 \mathrm{~mm} \times 38 \mathrm{~mm}$ (16 atm.) implantation was followed by a $3.5 \mathrm{~mm}$ $\times 20 \mathrm{~mm}(22 \mathrm{~atm}$.) and $3.75 \mathrm{~mm} \times 8 \mathrm{~mm}(20 \mathrm{~atm}$.) NCB post-dilation. Finally, a satisfying angiographic result was obtained (Fig. 2.1E).

\section{Case 2}

An 80-year-old female with hypertension, hyperlipidemia, diabetes type 2, paroxysmal atrial fibrillation, history of ischemic stroke was admitted to the cath-lab presenting NSTEMI. Coronary angiogram revealed heavily calcified significant long lesion of the dominant RCA with coexisting chronic occlusion of LAD (J-CTO score 3 points) (Fig. 2.2A) due to ongoing ischemia (resting chest pain) rescue PCI of RCA with 3 DES implantation was performed via right radial (AL 1.0 6F).

Five days later due to recurrent angina despite optimal medical therapy, CTO of LAD via left radial access was performed (EBU 7F). After wiring a distal part of the LAD with microcatheter and Gaia Second (Asahi-INTECC). Flow to artery was restored by inflation of $1.5 \mathrm{~mm} \times 20 \mathrm{~mm}$ balloon catheter and $2.5 \mathrm{~mm} \times 15 \mathrm{~mm} \mathrm{NCB}$ (Fig. 2.2B). However, significant under-expansion of $\mathrm{NCB}$ $3.5 \mathrm{~mm} \times 15 \mathrm{~mm}$ was observed in the proximal part of a lesion (Fig. 2.2C). 


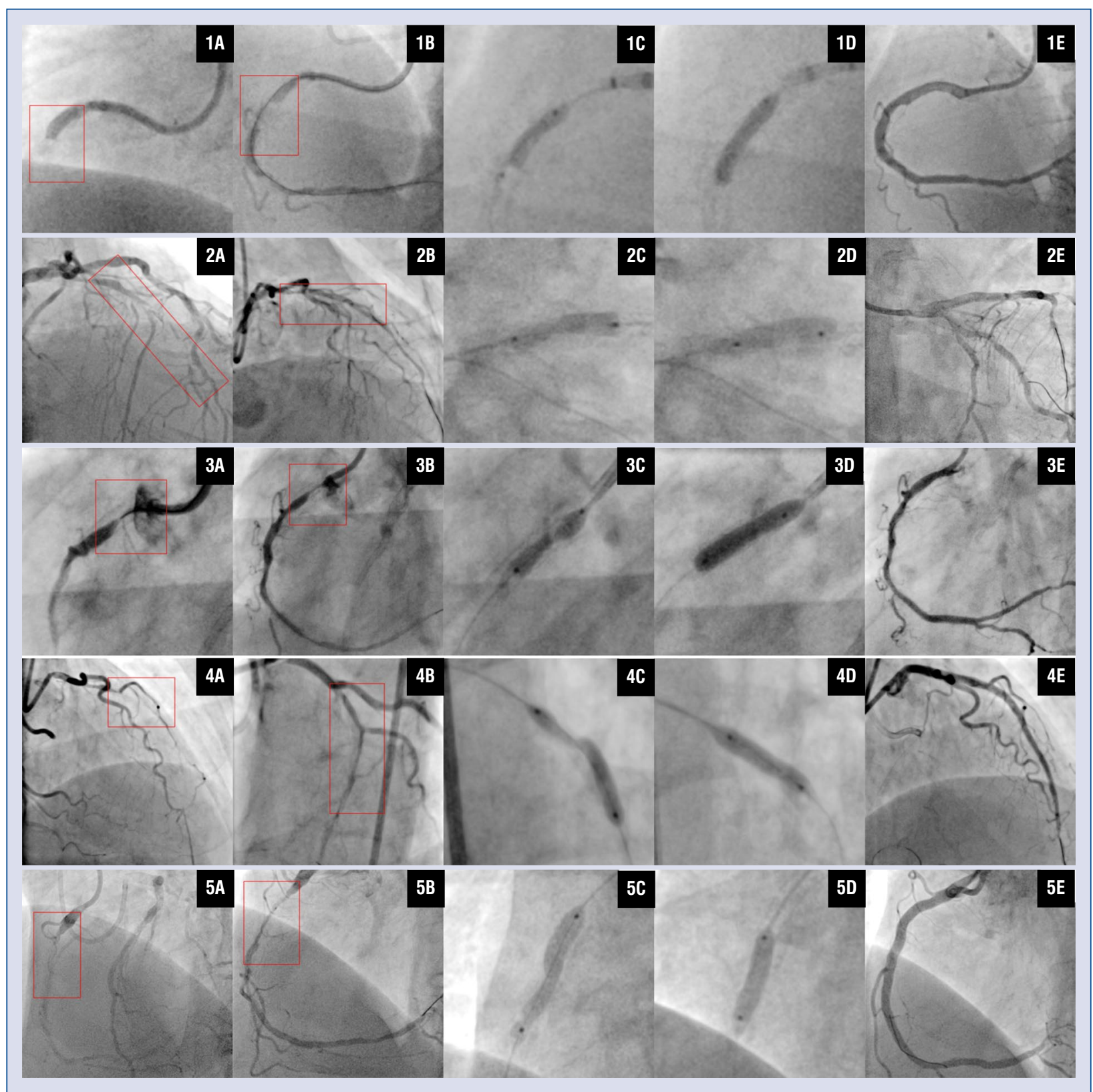

Figure 2. Series of cases: intervention images Case I: 1A. Primary chronic total occlusion (CTO) lesion; 1B. Undilatable lesion; 1C. Underexpansion of $3.0 \mathrm{~mm} \times 15 \mathrm{~mm}$ non-compliant balloon (NCB); 1D. Shockwave intravascular lithotripsy (S-IVL) balloon $3.0 \mathrm{~mm} \times 12 \mathrm{~mm}$; 1E. Final angiogram; Case II: 2A. Primary CTO lesion; 2B. Undilatable lesion; 2C. Underexpansion of $3.5 \mathrm{~mm} \times 15 \mathrm{~mm}$ NCB; 2D. S-IVL balloon $3.5 \mathrm{~mm} \times 12 \mathrm{~mm}$; 2E. Final angiogram; Case III: 3A. Primary CTO lesion; 3B. Undilatable lesion; 3C. Underexpansion of $3.5 \mathrm{~mm} \times 15 \mathrm{~mm}$ NCB; 3D. S-IVL balloon $3.5 \mathrm{~mm} \times 12 \mathrm{~mm}$; 3E. Final angiogram; Case IV: 4A. Primary CTO lesion; 4B. Undilatable lesion; 4C. Underexpansion of $3.5 \mathrm{~mm} \times 20 \mathrm{~mm}$ NCB; 4D. S-IVL balloon $3.5 \mathrm{~mm} \times 12 \mathrm{~mm}$; 4E. Final angiogram; Case V: 5A. Primary CTO lesion; 5B. Undilatable lesion; 5C. Underexpansion of $3.5 \mathrm{~mm} \times 20 \mathrm{~mm} \mathrm{NCB}$; 5D. S-IVL balloon $3.5 \mathrm{~mm} \times 12 \mathrm{~mm}$; $5 E$. Final angiogram.

Hence, S-IVL $(3.5 \times 12 \mathrm{~mm})$ with full expansion after 40 pulses of therapy was performed (Fig. 2.2D) and subsequent rapture of S-IVL balloon catheter without any sequelae. Three overlapping DESs: $2.5 \mathrm{~mm} \times 32 \mathrm{~mm} ; 3.0 \mathrm{~mm} \times 24 \mathrm{~mm}$, and $3.5 \mathrm{~mm} \times$ $16 \mathrm{~mm}$ were implanted with final post-dilated with
$3.5 \mathrm{~mm} \mathrm{NCB}$ (22 atm) and Thrombolysis in Myocardial Infarction 3 flow at the end of the procedure (Fig. 2.2E).

\section{Case 3}

A 66-year-old female, with hypertension, hyperlipidemia, diabetes type 2 , with lower ex- 
tremity peripheral artery disease (PAD), history of myocardial infarction with ST-segment elevation myocardial infarction myocardial infarction (STEMI) treated percutaneously with implantation of 3 DES to RCA, with subsequent scheduled implantation of 3 DES to LAD 11 years ago, was admitted to hospital with the symptoms of dyspnea and chest pain (II class in the CCS scale) despite optimal medical therapy. Magnetic resonance imaging revealed persistent viability of myocardium in the area of the inferior wall.

Coronary angiogram revealed: CTO of RCA in previously implanted stents (Fig. 2.3A) with no significant lesion in the left coronary system. By right radial access CTO-PCI was performed with successful crossing lesion with Gaia Second (Asahi-INTECC), after an exchange of guidewires the flow in RCA was restored with $1.0 \mathrm{~mm} \times 15$ $\mathrm{mm}$ (18 atm) baloon catheter (Fig. 2.3B). However, significant underexpansion of NCB $3.5 \mathrm{~mm} \times 15$ $\mathrm{mm}$ balloon catheter at $22 \mathrm{~atm}$ in proximal stent was observed (Fig. 2.3C). Therefore the S-IVL catheter $3.5 \mathrm{~mm} \times 12 \mathrm{~mm}$ was used. After the application of 80 ultrasonic pulses, full expansion was obtained (Fig. 2.3D). In the next step in the previously implanted DES, NCB $4.0 \mathrm{~mm} \times 15 \mathrm{~mm}$ was performed (22 atm) with subsequent implantation DES $4.0 \mathrm{~mm} \times 15 \mathrm{~mm}(16 \mathrm{~atm})$.

After restoring a flow to RCA a significant lesion in the distal part of RCA was revealed. It was predilatated with NCB $2.5 \mathrm{~mm} \times 15 \mathrm{~mm}(16 \mathrm{~atm})$ and was followed by DES $2.75 \mathrm{~mm} \times 15 \mathrm{~mm}(14 \mathrm{~atm})$ implantation. Finally, a satisfying angiographic result was obtained (Fig. 2.3E).

\section{Case 4}

62-year-old female with hypertension, hyperlipidemia, rheumatoid arthritis and hypothyroidism was admitted to hospital due to recurrent angina class II CCS. Pre-PCI echocardiography revealed mild contractility disorders in the area of the intraventricular septum with preserved global ejection fraction of the left ventricular. Coronary angiogram revealed CTO of the middle part of LAD (J-CTO score 3) (Fig. 2.4A).

Percutaneous coronary intervention via right femoral access Ebu 3.5 7F and contralateral injection by right radial AL1.0 was performed (7F). Using the anterograde wire escalation technique the distal part of LAD was achieved with Progress 140 (Abbott Vascular) and microcatheter. The flow was restored by inflation of balloon catheter $2.0 \mathrm{~mm}$ $\times 15 \mathrm{~mm}$ (16 atm) (Fig. 2.4B). Despite previous lesion preparation, a significant "dogbone effect" on the NCB $3.5 \mathrm{~mm} \times 20 \mathrm{~mm}$ (22 atm) (Fig. 2.4C) was observed. Thus, the S-IVL catheter $3.5 \mathrm{~mm}$ $\times 12 \mathrm{~mm}$ was used and after the application of 30 ultrasonic pulses, full expansion was obtained (Fig. 2.4D). Three overlapping DESs $3.5 \mathrm{~mm} \times$ $18 \mathrm{~mm} ; 3.0 \mathrm{~mm} \times 48 \mathrm{~mm}$ and $2.5 \mathrm{~mm} \times 18 \mathrm{~mm}$ (16 atm) implantation was followed by a $4.0 \mathrm{~mm} \times$ $8 \mathrm{~mm}(22 \mathrm{~atm}) \mathrm{NCB}$ postdilation. Finally, a satisfying angiographic result was obtained (Fig. 2.4E).

\section{Case 5}

68-year-old male with hypertension, hyperlipidemia, diabetes type 2, history of NSTEMI 6 months prior treated with PCI and DES implantation to the LAD and circumflex artery was admitted to hospital to perform stage CTO-RCA (J-CTO score 2) (Fig. 2.5A). Control echocardiography revealed slight contractility disorders in the area of the inferior wall with preserved left ventricular systolic function (ejection fraction 50\%).

Percutaneous coronary intervention was performed via right radial access AL $1.07 \mathrm{~F}$ with contralateral injection by left radial Ebu 3.5 7F. The CTO lesion was crossed with Gaia Third (AsahiINTECC) and microcatheter, after wire exchange on extra support successful predilatation of a lesion with inflation $1.5 \mathrm{~mm} \times 20 \mathrm{~mm}$ balloon catheter and $2.5 \mathrm{~mm} \times 15 \mathrm{~mm} \mathrm{NCB}$ was performed (Fig. 2.5B). However significant underexpansion of $\mathrm{NCB}$ $3.5 \mathrm{~mm} \times 20 \mathrm{~mm}(22 \mathrm{~atm})$ was observed (Fig. $2.5 \mathrm{C}$ ). As result, the S-IVL $3.5 \mathrm{~mm} \times 12 \mathrm{~mm}$ balloon was then passed and 4 cycles of lithotripsy were delivered (Fig. 2.5D). Two overlapping DES were implanted to RCA $-3.5 \mathrm{~mm} \times 26 \mathrm{~mm}(16 \mathrm{~atm})$; $3.5 \mathrm{~mm} \times 40 \mathrm{~mm}$ (14 atm). Additional postdilatation with NCB $4.0 \mathrm{~mm} \times 15 \mathrm{~mm}(20 \mathrm{~atm})$ was performed. Due to what was revealed in control angiogram, a significant lesion in the distal part of RCA after predilatation with $3.0 \mathrm{~mm} \times 15 \mathrm{~mm}$ $\mathrm{NCB}$, thus DES $3.0 \mathrm{~mm} \times 24 \mathrm{~mm}$ was implanted with reasonable angiographic resolution (Fig. 2.5E).

\section{Results}

The present case-series registry includes 5 patients with successful CTO procedures with heavy calcifications within the CTO — body which primary was undilatable with NCB treated with S-IVL (Table 1). Details on the clinical, procedural, and postprocedural characteristics are provided. All the patients were at "difficult" or "very difficult" stage in the degree of difficulty according to the $\mathrm{J}$-CTO with an average of 2.6 points. On average, patients undergoing the $\mathrm{CTO}$ procedure received 
Table 1. Clinical, procedural, and postprocedural characteristics of patients.

\begin{tabular}{lccccc}
\hline Clinical data & Case 1 & Case 2 & Case 3 & Case 4 & Case 5 \\
\hline Age [years] & 66 & 80 & 66 & 62 & 68 \\
Hypertension & Yes & Yes & Yes & Yes & Yes \\
Type 2 diabetes mellitus & Yes & Yes & No & No & Yes \\
Hyperlipidemia & Yes & Yes & Yes & Yes & Yes \\
Atrial fibrillation & No & Yes & No & No & No \\
Post PCl status & Yes & Yes & Yes & No & Yes \\
Primary diagnosis & CAD-CCS & CAD-UA & CAD-CCS & CAD-CCS & CAD-CCS \\
& II* & CCS III* & II* & II* & I** \\
Treated vessel & RCA & LAD & RCA & LAD & RCA \\
Access & $7 F$ FEM & 7 RAD & $7 F$ RAD & 7 FEM & 7 FAD \\
J-CTO score & 3 & 3 & 1 & 3 & 2 \\
Syntax score & 10 & 29,5 & 10 & 15,5 & 14 \\
IVL diameter [mm] & 3.0 & 3.5 & 3.5 & 3.5 & 3.5 \\
Number of pulses & 80 & 40 & 80 & 30 & 40 \\
DES size [mm] & $3.0 \times 38$ & $3.5 \times 16$ & $4.0 \times 15$ & $3.5 \times 18$ & $3.5 \times 40$ \\
DES pressure [atm] & 16 & 16 & 15 & 16 & 14 \\
Amount of contrast [mL] & 140 & 300 & 150 & 320 & 300 \\
Radiation dose [mGy] & 1657 & 1416 & 1382 & 1649 & 1611 \\
Fluoroscopy time [min] & 26.2 & 24.1 & 17.5 & 22.4 & 37.5 \\
\hline
\end{tabular}

CAD-CSS II - stable coronary artery disease in second class according to Canadian Cardiovascular Society; DES — drug eluting stent; FEM - femoral; IVL — intravascular lithotripsy; J-CTO — Japanese Multicenter CTO Registry; LAD — left anterior descending; PCI — percutaneous coronary intervention; RAD — radial; RCA — right coronary artery; UA — unstable angina

$242 \mathrm{~mL}(140 \mathrm{~mL}-320 \mathrm{~mL})$ of contrast - no postprocedural renal failure was noticed and absorbed 1543 mGy (1382 mGy - 1657 mGy) of radiation. In 1 case peri-procedural complication occurred. After the application of 40 sonic pulses, an S-IVL balloon catheter rapture we observed without any consequences for the patient. In the short-term followup period including the first 30 days, no cases of acute in-stent thrombosis or target lesion failure were noted. There was no case of the in-hospital MACCE nor MACCE observed within the 30 days after the intervention. The majority of procedures were performed by the radial approach $(7 \mathrm{~F})$

\section{Discussion}

This is, according to available research, is among the first-in-man case series studies to demonstrate the efficacy and safety of use S-IVL during the PCI-CTO procedures in CAD. So far, in the literature, mainly single case reports can be found $[11,12]$ and one recently published higher number study [13] using the intravascular lithotripsy as a part of the armamentarium in CTO procedures. Data suggest that undergoing successful CTO revascularization, compared to unsuccessful CTO recanalization, is associated with clinical benefit as well as improvement in long-term outcome [14]. As it was revealed, heavy calcifications are associated with lower success rate, and higher complication rates of CTO procedures [15]. Unsuccessful crossing through the occlusion with a guidewire is the most common mechanism of CTO-PCI failure [16]. However, another frequently observed mechanism of the CTO-PCI failure is device-uncrossable CTO lesions, defined as an inability of passage of a balloon after successful guidewire crossing (balloon uncrossable lesions) or an inability to expand fully the catheter despite the use of multiple balloon inflations (balloon undilatable lesions). For lesions that are not balloon-crossable, RA or orbital atherectomy are justifiable options. Balloon undilatable lesions are technically demanding and associated with worse outcomes. Prevalence of this phenomena is rater common $(6-12 \%$ of all CTO procedures) [17, 18].

Adequate preparation in such lesions is critical to avoid the short- and long-term complications. When inadequate, it can result in suboptimal stent expansion or fracture as well as a higher rate of stent thrombosis and in-stent restenosis. Currently, there are several therapeutic options to 
manage this clinical problem. Armamentarium for calcified lesion preparation is varied and consists of specialized balloon technology or atherectomy devices. Recently McQuillan et al. [19] proposed a clinical algorithm of different techniques that can be used in resistant lesions. The first line in the step-wise approach, using a different kind of balloon catheter was proposed. Besides classical NCBs, their algorithm recommends the use of ultrahigh-pressure balloons - OPN balloon or cutting/scoring balloons. As a second line, they suggest using an atherectomy device (rotational, orbital, or laser). In case of failure, the use of the S-IVL device is proposed, although as it was mentioned before there are only a few reports [20, 21] of such complex procedures. Such a stepwise approach allows for increasing the number of successful procedures, however, it increases the periprocedural complication rate. Especially when a more invasive strategy is used [22].

Unlike in the case of balloon uncrossable lesions where calcification occurs mainly superficially, causing occlusion of the inner lumen of the vessel, balloon undilatable lesions are more likely associated with the presence of profound calcium deposits. Therefore, classical methods of lesion preparation-balloon or atherectomy devices focused on the superficial plaque modification often remains insufficient. To date, the main method of management with these issues has been based on an escalation of device sizes. It was inextricably linked with the increased rate of acute peri-procedural complications: slow/no flow phenomena, dissection, or perforation of the vessel. Furthermore, this aggressive approach often requires the use of femoral access. It may partially result from better guide support and the necessity of larger burr size use. On the one hand, recent data suggests [23] that trans radial access is increasingly being used for CTO PCI and is associated with a similar outcome and a lower rate of major bleeding. On the other hand, a higher level of J-CTO score accompanied by an increased level of calcium deposits is responsible for the growth of the femoral access rate. By using S-IVL devices, it is possible to pass-by the use of an atherectomy device (with potentially large burr size) and potentially de-escalate the level of necessary "support need" from the guiding catheter which results in an increased rate of radial access procedures. The data from our case series seems to be consistent with this thesis despite quite a high average J-CTO score (2.4) a majority of cases were performed by radial access (7F). This benefit of the S-IVL device is related to the mechanism of action which is a combination of several physical phenomena: amplitude of the pressure, stretching wave, cavitation, and lead to the defragmentation of deep calcium nodules [24]. In conclusion, S-IVL should rather be chosen instead of rotational devices in non-critical focal lesions with deep calcium deposits, particularly not susceptible to the predilatation NCB parallel to the vessels size. Initial data from real-life registries seems to support this thesis [25]. Despite all of this, the bulky nature of S-IVL must be taken into consideration, before proper guiding selection. Operators should also be aware of the size limitations of the S-IVL system ( short $12 \mathrm{~mm}$ balloon catheters in diameter range $2.5-4.0 \mathrm{~mm}$ ) and a restrained number of delivered ultrasonic pulses (80).

Since intravascular lithotripsy is a relatively novel method, safety concerns are not unfounded. In our registry, only one acute complication related to this device was observed - the burst of the S-IVL balloon. This device failure was described previously, it is rather common and hardly ever causes any sequelae [25, 26]. Nevertheless, some data suggest that S-IVL can induce ventricular arrhythmias [27] and future studies focused on the safety issue of this therapy are necessary. However, in the present "real-life" study, there is a lack of data from intravascular imaging (the decision to use intravascular ultrasound/optical coherence tomography was left to the discretion of the operators), it was presumed that it would provide valuable and precise information to increase the safety and efficacy of CTO-S-IVL procedures.

Although experience with S-IVL and calcified CTO lesion is unproven and limited mainly to lower limb arteries [28], the present early experience is favorable and provides encouraging preliminary data for future studies. Despite the current lack of strong data, the present case study suggests that S-IVL can be effective and safe to handle the balloon-undilatable lesions in the CTO.

\section{Conclusions}

In this case series describing the application of S-IVL in the PCI-CTO procedures, it was shown that the device was a useful tool to assist interventional cardiologists in complex calcified CTO lesions.

\section{Conflict of interest: None declared}




\section{References}

1. Kim SH, Behnes M, Mashayekhi K, et al. Prognostic impact of percutaneous coronary intervention of chronic total occlusion in acute and periprocedural myocardial infarction. J Clin Med. 2021; 10(2), doi: 10.3390/jcm10020258, indexed in Pubmed: 33445664.

2. Galassi AR, Werner GS, Boukhris M, et al. Percutaneous recanalisation of chronic total occlusions: 2019 consensus document from the EuroCTO Club. EuroIntervention. 2019; 15(2): 198-208, doi: 10.4244/EIJ-D-18-00826, indexed in Pubmed: 30636678.

3. Othman H, Seth M, Zein R, et al. BMC2 Investigators. Percutaneous Coronary Intervention for Chronic Total OcclusionThe Michigan Experience: Insights From the BMC2 Registry. JACC Cardiovasc Interv. 2020; 13(11): 1357-1368, doi: 10.1016/j. jcin.2020.02.025, indexed in Pubmed: 32417095.

4. Jang WJ, Yang JH, Choi SH, et al. Long-term survival benefit of revascularization compared with medical therapy in patients with coronary chronic total occlusion and well-developed collateral circulation. JACC Cardiovasc Interv. 2015; 8(2): 271-279, doi: 10.1016/j.jcin.2014.10.010, indexed in Pubmed: 25700750.

5. Riley RF, Sapontis J, Kirtane AJ, et al. Prevalence, predictors, and health status implications of periprocedural complications during coronary chronic total occlusion angioplasty. EuroIntervention. 2018; 14(11): e1199-e1206, doi: 10.4244/EIJ-D-17-00976, indexed in Pubmed: 29808821.

6. Morino $\mathrm{Y}$, Abe M, Morimoto T, et al. J-CTO Registry Investigators. Predicting successful guidewire crossing through chronic total occlusion of native coronary lesions within 30 minutes: the J-CTO (Multicenter CTO Registry in Japan) score as a difficulty grading and time assessment tool. JACC Cardiovasc Interv. 2011; 4(2): 213-221, doi: 10.1016/j.jcin.2010.09.024, indexed in Pubmed: 21349461

7. Huisman J, van der Heijden LC, Kok MM, et al. Impact of severe lesion calcification on clinical outcome of patients with stable angina, treated with newer generation permanent polymercoated drug-eluting stents: A patient-level pooled analysis from TWENTE and DUTCH PEERS (TWENTE II). Am Heart J. 2016; 175: 121-129, doi: 10.1016/j.ahj.2016.02.012, indexed in Pubmed: 27179731.

8. Wańha W, Januszek R, Kołodziejczak M, et al. Procedural and 1-year outcomes following large vessel coronary artery perforation treated by covered stents implantation: Multicentre CRACK registry. PLoS One. 2021; 16(5): e0249698, doi: 10.1371/journal. pone.0249698, indexed in Pubmed: 33979357.

9. Elrayes MM, Xenogiannis I, Nikolakopoulos I, et al. An algorithmic approach to balloon-uncrossable coronary lesions. Catheter Cardiovasc Interv. 2021; 97(6): E817-E825, doi: 10.1002/ ccd.29215, indexed in Pubmed: 32865855.

10. Ali ZA, Nef H, Escaned J, et al. Safety and effectiveness of coronary intravascular lithotripsy for treatment of severely calcified coronary stenoses: the disrupt CAD II study. Circ Cardiovasc Interv. 2019; 12(10): e008434, doi: 10.1161/CIRCINTERVENTIONS.119.008434, indexed in Pubmed: 31553205.

11. Azzalini L, Bellini B, Montorfano M, et al. Intravascular lithotripsy in chronic total occlusion percutaneous coronary intervention. EuroIntervention. 2019; 15(11): e1025-e1026, doi: 10.4244/ EIJ-D-19-00175, indexed in Pubmed: 31012852.

12. Yeoh J, Hill J, Spratt JC. Intravascular lithotripsy assisted chronic total occlusion revascularization with reverse controlled antegrade retrograde tracking. Catheter Cardiovasc Interv. 2019; 93(7): 1295-1297, doi: 10.1002/ccd.28165, indexed in Pubmed: 30838746.

13. Øksnes A, Cosgrove C, Walsh S, et al. Intravascular lithotripsy for calcium modification in chronic total occlusion percutaneous coronary intervention. J Interv Cardiol. 2021; 2021: 9958035, doi: 10.1155/2021/9958035, indexed in Pubmed: 34239390.
14. Borgia F, Viceconte N, Ali O, et al. Improved cardiac survival, freedom from MACE and angina-related quality of life after successful percutaneous recanalization of coronary artery chronic total occlusions. Int J Cardiol. 2012; 161(1): 31-38, doi: 10.1016/j. ijcard.2011.04.023, indexed in Pubmed: 21722979.

15. Karacsonyi J, Karmpaliotis D, Alaswad K, et al. Impact of calcium on chronic total occlusion percutaneous coronary interventions. Am J Cardiol. 2017; 120(1): 40-46, doi: 10.1016/j.amjcard.2017.03.263, indexed in Pubmed: 28499595.

16. Christopoulos G, Wyman RM, Alaswad K, et al. Clinical utility of the Japan-chronic total occlusion score in coronary chronic total occlusion interventions: results from a multicenter registry. Circ Cardiovasc Interv. 2015; 8(7): e002171, doi: 10.1161/CIRCINTERVENTIONS.114.002171, indexed in Pubmed: 26162857.

17. Patel SM, Pokala NR, Menon RV, et al. Prevalence and treatment of ,balloon-uncrossable” coronary chronic total occlusions. J Invasive Cardiol. 2015; 27(2): 78-84, indexed in Pubmed: 25661758.

18. Tajti P, Burke MN, Karmpaliotis D, et al. Prevalence, presentation and treatment of ,balloon undilatable' chronic total occlusions: insights from a multicenter US registry. Catheter Cardiovasc Interv. 2018; 91(4): 657-666, doi: 10.1002/ccd.27510, indexed in Pubmed: 29359452.

19. McQuillan C, Jackson MWP, Brilakis ES, et al. Uncrossable and undilatable lesions-A practical approach to optimizing outcomes in PCI. Catheter Cardiovasc Interv. 2021; 97(1): 121-126, doi: 10.1002/ccd.29001, indexed in Pubmed: 32453918.

20. Włodarczak A, Kulczycki J, Furtan $€$, et al. Rotational atherectomy and intravascular lithotripsy: two methods versus a single lesion. Kardiol Pol. 2021; 79(6): 712-713, doi: 10.33963/KP.15962, indexed in Pubmed: 33890748.

21. Włodarczak A, Rola P, Barycki M, et al. Rota-lithotripsy: a novel bail-out strategy for calcified coronary lesions in acute coronary syndrome. The first-in-man experience. J Clin Med. 2021; 10(9), doi: 10.3390/jcm10091872, indexed in Pubmed: 33925916.

22. Azzalini L, Dautov R, Ojeda S, et al. Long-term outcomes of rotational atherectomy for the percutaneous treatment of chronic total occlusions. Catheter Cardiovasc Interv. 2017; 89(5): 820-828, doi: 10.1002/ccd.26829, indexed in Pubmed: 28029214.

23. Tajti P, Alaswad K, Karmpaliotis D, et al. Procedural outcomes of percutaneous coronary interventions for chronic total occlusions via the radial approach. JACC: Cardiovascular Interventions. 2019; 12(4): 346-358, doi: 10.1016/j.jcin.2018.11.019.

24. Ogden JA, Tóth-Kischkat A, Schultheiss R. Principles of shock wave therapy. Clin Orthop Relat Res. 2001(387): 8-17, doi: 10.1097/00003086-200106000-00003, indexed in Pubmed: 11400898.

25. Rola P, Włodarczak A, Kulczycki JJ, et al. Feasibility of the intravascular lithotripsy in coronary artery disease. Short-term outcomes of the Lower-Silesia Shockwave Registry. Kardiol Pol. 2021 [Epub ahead of print], doi: 10.33963/KP.a2021.0093, indexed in Pubmed: 34415567.

26. Aksoy A, Salazar C, Becher MU, et al. Intravascular lithotripsy in calcified coronary lesions: a prospective, observational, multicenter registry. Circ Cardiovasc Interv. 2019; 12(11): e008154, doi: 10.1161/CIRCINTERVENTIONS.119.008154, indexed in Pubmed: 31707803.

27. Karimi Galougahi K, Patel S, Shlofmitz RA, et al. Calcific plaque modification by acoustic shock waves: intravascular lithotripsy in coronary interventions. Circ Cardiovasc Interv. 2021; 14(1): e009354, doi: 10.1161/CIRCINTERVENTIONS.120.009354, indexed in Pubmed: 32907343.

28. Holden A. The use of intravascular lithotripsy for the treatment of severely calcified lower limb arterial CTOs. J Cardiovasc Surg (Torino). 2019; 60(1): 3-7, doi: 10.23736/S0021-9509.18.10779-8, indexed in Pubmed: 30411605. 